\title{
STUDY OF TREATMENT OUTCOME OF TUBERCULOSIS PATIENTS PLACED FOR TREATMENT UNDER DIRECTLY OBSERVED THERAPY SHORT COURSE (DOTS) AT A TUBERCULOSIS UNIT, KARAD, WESTERN MAHARASHTRA
}

\author{
Raju Hanumant Patil1, Vaishali V. Raje²
}

${ }_{1}^{1}$ Postgraduate Student, Department of Community Medicine, Krishna Institution of Medical Sciences, Deemed University, Karad. ${ }^{2}$ Professor, Department of Community Medicine, Krishna Institution of Medical Sciences, Deemed University, Karad.

\section{ABSTRACT}

\section{BACKGROUND}

Aim- To know the treatment outcome of all TB patients registered under Tuberculosis Unit, Karad.

Objectives- To study the prevalence of different types of TB cases under Karad Tuberculosis Unit and to study the outcome of all registered TB cases at Karad Tuberculosis Unit.

\section{MATERIALS AND METHODS}

This is a record based, cross sectional study which included all types of tuberculosis cases registered for treatment at Karad Tuberculosis Unit for the year 2014. Data was collected by referring quarterly reports of RNTCP.

Statistical Analysis- Data was entered in Excel, and proportions and various performance indicators were calculated for the year 2014.

\section{RESULTS}

The sputum conversion rate at the end of IP among Cat I Cases was 91.1\%. Among Cat II cases, the sputum conversion rate at the end of IP was found to be 50\%. Among the pulmonary tuberculosis cases, $61 \%$ was the cure rate with $14 \%$ of treatment completion. The success rate was $74.5 \%$. The death rate at Karad TU was very high at $13.8 \%$ with high failure rate $6.5 \%$ and default rate $4.5 \%$. The transferred out rate was $0.8 \%$. Among extrapulmonary tuberculosis cases, the success rate was $90.3 \%$ with a high death rate of $5.5 \%$. The default rate of $2.8 \%$, transferred out rate of $1.4 \%$ and zero percent failure rate were reported in year 2014.

\section{CONCLUSION}

The suspicion rate of $>220 /$ lakh/year was achieved, sputum positive rate of $5 \%-15 \%$ was achieved although on lower side, new sputum positive target of $50 \%$ was also achieved.

\section{KEYWORDS}

DOTS, Revised National Tuberculosis Control Programme, Tuberculosis Unit.

HOW TO CITE THIS ARTICLE: Patil RH, Raje VV. Study of treatment outcome of tuberculosis patients placed for treatment under directly observed therapy short course (DOTS) at a tuberculosis unit, Karad, Western Maharashtra. J. Evolution Med. Dent. Sci. 2017;6(46):3609-3613, DOI: 10.14260/Jemds/2017/778

BACKGROUND
Tuberculosis is a chronic, communicable, infectious disease caused by Mycobacterium tuberculosis bacilli usually affecting lungs, primarily resulting in pulmonary tuberculosis. It can affect any organ or system in the body such as bones, meninges, intestine, lymph nodes, etc. leading to extrapulmonary tuberculosis. This age old disease is not only a public health problem but also a social and an economic problem for mankind. ${ }^{1}$

Tuberculosis is a very ancient disease of mankind; its description has been found in Hippocrates (460-377 BC) observation, the ancient Buddhist and Chinese writing. Even

Financial or Other, Competing Interest: Dr. Raje reports grants from Revised National Tuberculosis Control programme during the conduct of the study.

Submission 24-04-2017, Peer Review 27-05-2017,

Acceptance 02-06-2017, Published 08-06-2017.

Corresponding Author:

Dr. Raju Hanumant Patil,

Department of Community Medicine

KIMS, Deemed University, Karad,

Maharashtra, India.

E-mail:drrajhp@gmail.com

DOI: $10.14260 /$ jemds $/ 2017 / 778$ the 500 BC old Egyptian mummies showed the evidence for tuberculosis. Tuberculosis is known by many names in IndiaKshaya Roga, Tapedik, Rajayakshma and in Western world it is known as phthisis. ${ }^{2}$

A German scientist, Robert Koch on 24th March 1882 discovered the rod-shaped bacteria causing tuberculosis which won him the Noble prize in Physiology and Medicine in 1905. In 1890, he produced tuberculin, an extract of dead tubercle bacilli, used for a diagnostic test for tuberculosis infection. ${ }^{1,3}$ Rifampicin was developed and its important role was confirmed in the therapy for Tuberculosis in 1968. NTCP was launched. ${ }^{4}$

NTCP was reviewed and government of India introduced RNTCP in 1992 with objectives of $85 \%$ cure rate and $70 \%$ case finding. Since the implementation of RNTCP was done phase wise throughout the country, the case detection and cure rates were found to be improved according to many studies $^{1}$. The Karad is an agriculturally rich area with a population of 4,24,652. The Karad tuberculosis unit is located in Sub-District Hospital, Karad (Cottage Hospital, Karad) under Dist. Tuberculosis Centre, Satara, Western Maharashtra. This tuberculosis unit is connected to Medical College and Tertiary Care Centre, Krishna Institution of Medical Sciences, Krishna Hospital, which is a 1,100-bedded 
hospital. Thus, this study was an attempt to evaluate functioning of RNTCP at Sub-Dist. Level, Karad.

\section{Aim}

To know the treatment outcome of all TB patients registered under Tuberculosis Unit, Karad.

\section{Objectives}

1. To study the prevalence of different types of TB cases under Karad Tuberculosis Unit.

2. To study the outcome of all registered TB cases at Karad Tuberculosis Unit.

\section{MATERIALS AND METHODS}

This is a record based, cross sectional study. The study included all types of tuberculosis cases registered for treatment at Karad Tuberculosis Unit for the year 2014. Data was collected by referring quarterly reports of RNTCP.

\section{Data Collection}

The functioning of Karad Tuberculosis Unit under Revised National Tuberculosis Control Programme under District Satara, was studied for the year 2014. The data collection regarding performance of Tuberculosis Unit was carried out by obtaining information on diagnostic activities, treatment activities and treatment outcomes. All this information was collected by accessing the records maintained at the level of tuberculosis unit. Investigator visited tuberculosis unit and collected information through the laboratory registers, referral registers and treatment registers. All the information collected was entered in structured proforma.

\section{Statistical Analysis}

Data was entered in Excel and proportions and various performance indicators were calculated for years 2014 .

Operational definitions for New case, Treatment after default, Failure case, Pulmonary Tuberculosis, SmearPositive, Pulmonary tuberculosis, Smear-negative, Extrapulmonary tuberculosis cases, Treatment outcomes like Cured, Treatment completed, Died, Failure, Defaulted and Transferred out were considered as per the guidelines of Revised National Tuberculosis Programme.,2,3

\section{RESULTS}

The Karad Tuberculosis Unit caters to a population of $4,24,653$ through 6 DMCs and 42 DOT centres. It was observed that the DMCs were covering more people than the RNTCP guidelines which is one TU per 5 lakh population and 2.5 lakh populations for tribal and hilly areas.

The case detection activities as depicted in Figure 1, it is observed that $99.6 \%$ patients out of $4.02 \%$ total chest symptomatic patients attending OPD were referred for sputum examination and among them only $6 \%$ were positive smear for tubercular bacilli. Repeat sputum examination was done on $3.2 \%$ patients with zero smear positive among them. The total new sputum positive cases at Karad TU for year 2014 were 6\% (Fig.1).

The Figure 2 depicts total TB case detection at Karad TU for the year 2014, it was observed that the new tuberculosis cases diagnosed were $84.4 \%$ and $15.6 \%$ were old sputum positive cases. The pulmonary TB cases were $82.7 \%$ and $17.3 \%$ were Extrapulmonary TB cases, the new sputum smear-positive cases registered at Karad TU for year 2014 were $57.8 \%$ and only $9.4 \%$ were new sputum smear-negative cases (Fig. 2).

\section{RNTCP Indices}

The Indices pertaining to case detection in Karad TU with a population of 4, 24, 652 and OPD of 100123 for the year 2014 had a suspicion rate of 944.5 per lakh population, the sputum positive rate 6 per 100 suspected cases of tuberculosis. The percentage of new sputum positive cases among new pulmonary tuberculosis was 86.1 per 100 new pulmonary tuberculosis cases and percentage of extrapulmonary tuberculosis among new tuberculosis cases was 20.5 per 100 new tuberculosis cases. The percentage of Old tuberculosis cases among total tuberculosis cases observed was 15.6 per 100 total tuberculosis cases. The annual case detection rate for the year 2014 was 82.9 per lakh population with annual new sputum positive rate of 56.8 per lakh population (Fig. 2).

It was seen that it's the male gender which has been affected more by the tuberculosis be it pulmonary $(11.4 \%)$ or extrapulmonary tuberculosis $(13.2 \%)$ compared to female pulmonary $(10.2 \%)$ and extrapulmonary $(11.4 \%)$ patients. (Fig. 3)

It was noted that the age wise distribution of pulmonary tuberculosis was high in the age group of more than 65 years age $(14.3 \%)$ followed by $14.1 \%$ in age group of $55-64$ years and $13.6 \%$ in $45-54$ years and $12.4 \%$ in $15-54$ years age group. (Fig. 4)

Among extrapulmonary tuberculosis cases highest proportion of cases belonged to age group of 15-24 years (20.8\%) and $17.6 \%$ from $45-54$ years group followed by $13.3 \%$ (35-44 yrs.) and $10.7 \%$ (25-34 yrs.). Overall it was observed that tuberculosis disease affecting the economic productive age groups. Among paediatric age group all cases (1.6\% of all TB cases) were affected by pulmonary tuberculosis and not a single case of extrapulmonary tuberculosis case was noted. (Fig. 4)

Among total 417 tuberculosis cases detected at Karad TU, twenty-four percentage of patient were referred out for treatment and seventy-six percentage of patients were pulmonary tuberculosis cases for the year 2014. (Fig. 5)

Total patients put on treatment at Karad TU were 319, among them $77 \%$ were pulmonary tuberculosis cases and remaining 23\% were extrapulmonary tuberculosis cases. Among pulmonary tuberculosis cases $74 \%$ belonged to Cat I and $26 \%$ were on Cat-II treatment. The sputum conversion rate at the end of IP among Cat I Cases was 91.1\%. Among Cat II cases, the sputum conversion rate at the end of IP was found $50 \%$. Among extrapulmonary tuberculosis cases, $97 \%$ were kept on Cat I and only 3\% on Cat II. (Table 1).

\section{Treatment Outcomes}

Among the pulmonary tuberculosis cases, $61 \%$ had cure with $14 \%$ of treatment completion. Thus, the success rate was $74.5 \%$. The death rate observed at Karad TU among pulmonary tuberculosis cases was very high $13.8 \%$ with high failure rate $(6.5 \%)$ and default rate $4.5 \%$. The transferred out rate was $0.8 \%$. Among extrapulmonary tuberculosis cases, the success rate was $90.3 \%$ who also showed a high death rate of $5.5 \%$ with $2.8 \%$ default rate, $1.4 \%$ transferred out rate and zero percent failure rate was reported in year 2014 . (Table 2). 


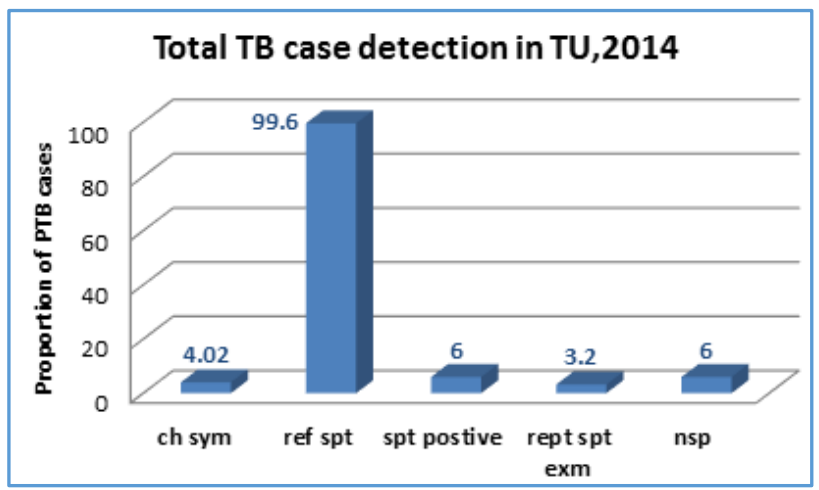

Figure 1. TB Case Detection Activities at Karad TU, 2014

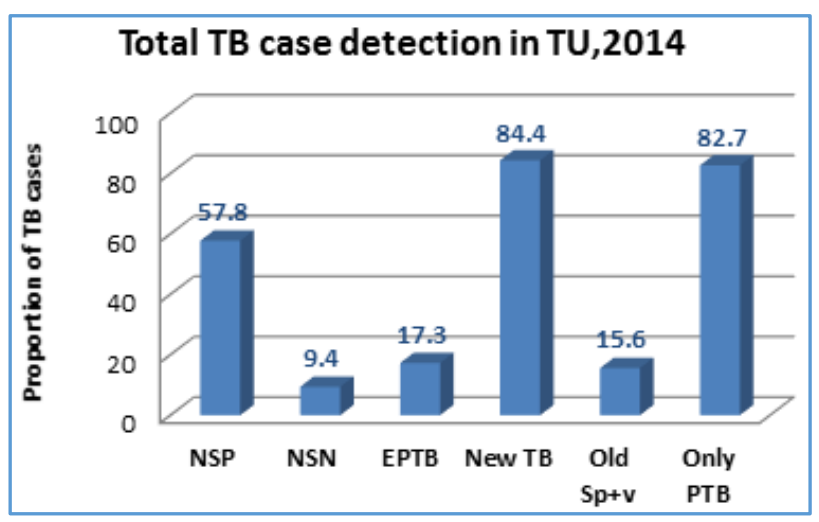

Figure 2. Total TB Case Detection Activities at Karad TU, 2014

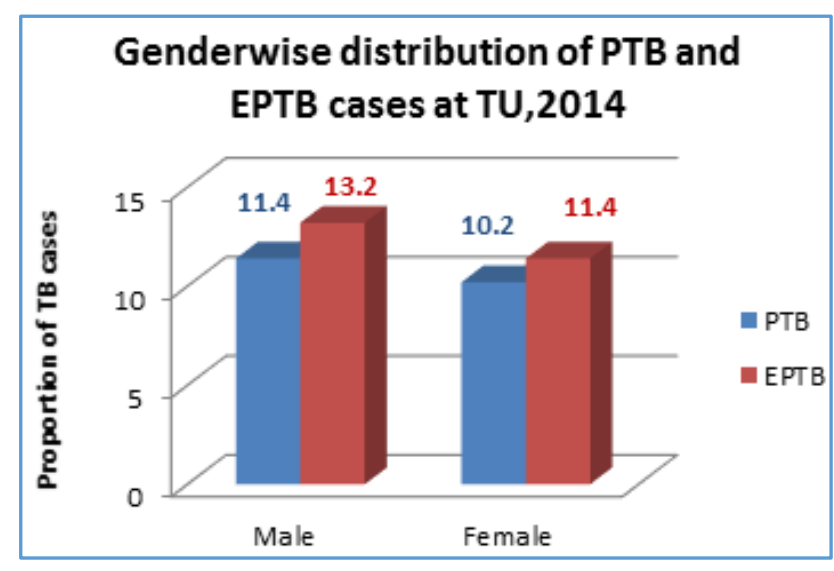

Figure 3. Gender Wise Distribution of PTB and EPTB Cases in 2014

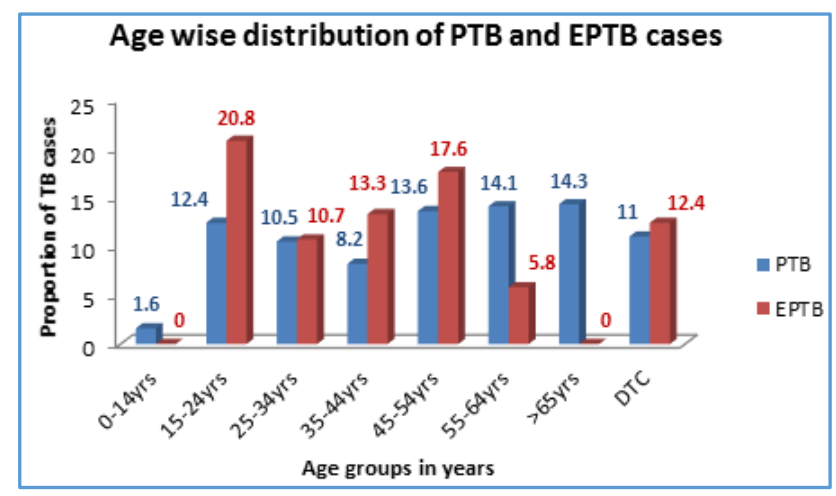

Figure 4. Showing Age wise Distribution of Pulmonary and Extrapulmonary TB cases at Karad TU (\%)

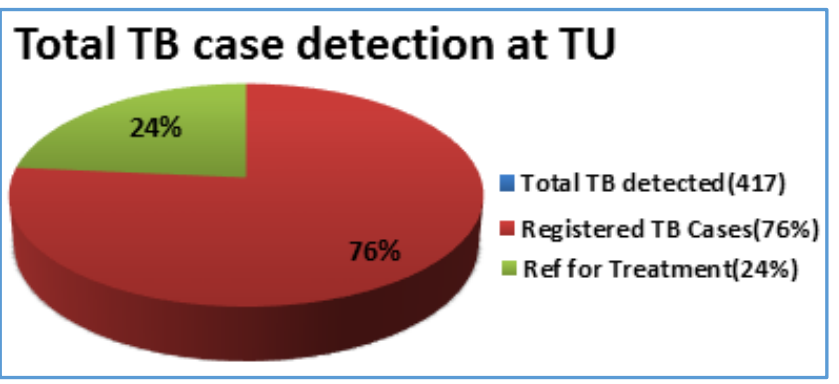

Figure 5. Treatment Activities of Pulmonary TB Cases

\begin{tabular}{|c|c|c|c|c|c|}
\hline $\begin{array}{c}\text { Type of } \\
\text { TB }\end{array}$ & $\begin{array}{c}\text { On Trt } \\
(\mathbf{n = 3 1 9 )}(\%)\end{array}$ & Cat-I & Cat-II & $\begin{array}{c}\text { Sp con } \\
\text { Cat-I }\end{array}$ & $\begin{array}{c}\text { Sp con } \\
\text { Cat-II }\end{array}$ \\
\hline PTB & $247(77)$ & $182(74)$ & $65(26)$ & 91.1 & 50 \\
\hline EPTB & $72(23)$ & $70(97)$ & $2(3)$ & - & - \\
\hline Table 1. Treatment Activities of Tuberculosis Cases at \\
Karad TU, 2014
\end{tabular}

\begin{tabular}{|c|c|c|c|c|c|c|c|}
\hline $\begin{array}{c}\text { Type } \\
\text { of TB }\end{array}$ & $\begin{array}{c}\text { TB } \\
\text { Cases } \\
\text { on Trt }\end{array}$ & Cure & $\begin{array}{c}\text { Trt } \\
\text { Complete }\end{array}$ & Death & Failure & $\begin{array}{c}\text { Trans- } \\
\text { ferred } \\
\text { out }\end{array}$ & Default \\
\hline PTB* $^{*}$ & 247 & 150 & 34 & 34 & 16 & 2 & 11 \\
$(77)$ & $(61)$ & $(13.8)$ & $(13.8)$ & $(6.5)$ & $(0.8)$ & $(4.5)$ \\
\hline EPTB $^{* *}$ & 72 & - & 65 & 4 & 0 & 1 & 2 \\
$(23)$ & $-70.3)$ & $(5.5)$ & $(0)$ & $(1.4)$ & $(2.8)$ \\
\hline \multicolumn{7}{|c|}{ Table 2. Treatment Outcome of Pulmonary } \\
\hline \multicolumn{7}{|c|}{ TB and EPTB at Karad TU, 2014 } \\
\hline
\end{tabular}

*Success Rate: 74.5\%, **Success Rate: 90.3

\section{DISCUSSION}

For year 2014, almost $23.6 \%$ of population visited Outpatients Department (OPD) at Karad Tuberculosis Units, among them chest symptomatic were $4.02 \%$ and among all the symptomatic cases, $99.6 \%$ cases were referred for sputum microscopy and among them only $6 \%$ were found sputum smear positive for tuberculosis. Similar finding regarding sputum positivity was reported by Navin Chandra M K et al ${ }^{4}(7.11 \%)$, whereas Ajay Kumar et $\mathrm{al}^{5}$ (26.4\%) reported very high sputum positivity than the present study. Though the tuberculosis suspicion rate was higher, the sputum positive rate was found less.

In the present study, newly detected PTB cases $(82.7 \%)$ were very high in comparison with S Bisoi et $\mathrm{al}^{6}$ who detected $67 \%$ new pulmonary tuberculosis cases and $33 \%$ extrapulmonary tuberculosis cases, whereas Abhijit Mukherjee et $\mathrm{al}^{7}$ reported $77.8 \%$ new pulmonary tuberculosis cases and $23.2 \%$ extrapulmonary tuberculosis cases among newly detected tuberculosis cases. In current study among all newly detected pulmonary tuberculosis cases, $86.07 \%$ were new sputum positive and $13.92 \%$ were sputum negative pulmonary tuberculosis cases. Abhijit Mukherjee et $\mathrm{al}^{7}$ found $50 \%$ were new sputum positive and $50 \%$ were sputum negative pulmonary tuberculosis cases among newly detected pulmonary tuberculosis cases. This high rate of sputum positivity may be due to the medical college which has a designated microscopic centre attached to the current tuberculosis unit.

The annualised new sputum positive case rate in the present study was $86 \%$, among NPTB cases, which was above the target ( $50 \%$ out of all new PTB) given by Revised National Tuberculosis Control Programme. ${ }^{8}$ 
As per the Revised National Tuberculosis Control Programme ${ }^{6}$ guidelines, annualised case detection rate should be $>220$ per lakh per year, whereas in year 2014 the annualised case detection rate at Karad TU was 82.9 per lakh population which was too less than the given target.

\section{Treatment Activities}

High proportion of pulmonary tuberculosis cases on Cat-I similar to the present study from $81 \%$ to $95.5 \%$ were observed by A Mishra et al, ${ }^{8}$ S L Chandha et al, ${ }^{9}$ Abhijit M et al, ${ }^{7}$ A L DaCosta et al. ${ }^{10}$

Almost similar sputum conversion rate by three months of Cat-I pulmonary tuberculosis cases was reported by Bawri $S$ et $\mathrm{al}^{11}(92 \%)$ and Gurpreet K et al ${ }^{12}$ (93.8\%). Simmi Tiwari et al $^{13}$ reported achievement below average $(88.8 \%)$ and $S$ Bisoi et $\mathrm{al}^{6}$ also found poor conversion rate (74.2\%) among new sputum positive cases.

A Mishra et $\mathrm{al}^{8}$ reported $56 \%$ of sputum conversion rate among re-treatment cases and Abhijit $\mathrm{M}$ et al,11 Md Shamim Akhtar et al have reported very low level of sputum conversion rate among re-treatment cases, in contrast to these studies Gurpreet $\mathrm{K}$ et $\mathrm{al}^{16}$ have reported highest sputum conversion rate among Cat-II patients (94.1\%). A low level of sputum conversion rate among Cat-II (50\%) patients in Karad tuberculosis unit may be due to majority of patients in Cat-II and they might have got infected with drug-resistant tuberculosis cases (MDR-TB) and referred to the tertiary care centre where medical college is located.

\section{Treatment Outcomes}

In the present study, the cure rate among pulmonary tuberculosis cases was more (61\%) when compared to a study conducted by Mahesh C et al ${ }^{15}(43.3 \%)$ whereas studies conducted by A. Mishra et al ${ }^{12}(85.04 \%)$ and S L Chadha et $\mathrm{al}^{13}(90 \%)$ had high cure rates among pulmonary tuberculosis cases. The success rate seen in the present study (74.5\%) was low as compared to the observation noted by $\mathrm{R}$ Prasad et al ${ }^{16}$ of $89.4 \%$, and default rate of $32.5 \%$ in a study by Mahesh $\mathrm{C}$ et al was very high compared to present study (4.5\%), but findings of $\mathrm{R}$ Prasad et al ${ }^{16}$ regarding default rate $(3.79 \%)$ was low compared to the present study. High death rate $(13.8 \%)$ was observed in the present study as against the findings of SL Chadha et $\mathrm{al}^{13}(0.93 \%)$ and the failure rate (6.5\%) was high in the present study among pulmonary TB cases in comparison with SL Chadha et al ${ }^{13}(1.5 \%)$ and $\mathrm{R}$ Prasad et al $^{16}(1.25 \%)$ but was less as compared to the findings of Mahesh $\mathrm{C}$ et $\mathrm{al}^{15}$ (9.3\%). Transferred out cases $(0.8 \%)$ were very less as compared to AL Da Costa et al ${ }^{10}$ (16.09\%).

Among extrapulmonary TB patients, the treatment completion rate in the present study was high in comparison to AL DaCosta et al ${ }^{10}(85.05 \%)$ but the death rate in their study was less $(2.29 \%)$, whereas both transferred out $(16.09 \%)$ and default rates $(12.65 \%)$ were very high compared to the present study.

\section{CONCLUSION}

Out of 4028 chest symptomatic patients attending OPD, 241 cases were new sputum positive, 39 cases were new sputum negative, 72 cases were extrapulmonary TB and 65 cases were old sputum positive. The suspicion rate of > 220/lakh/year was achieved (944.5/lakh/year), sputum positive rate of $5 \%-15 \%$ was achieved $(6 \%)$ although on lower side, New sputum positive target of $50 \%$ was also achieved (86.1\%).

The Karad tuberculosis unit reported low success rate $(74.5 \%)$ and high rates of death $(13.8 \%)$, failure $(6.5 \%)$ and default $(4.5 \%)$ in treatment outcome in PTB cases. Among extrapulmonary treatment outcome, treatment completion was $90.3 \%$ with high death rate, this might be due to majority of the cases reported to the peripheral institution under Karad TU, a tertiary care centre which receives severe cases of pulmonary tuberculosis as well as the absence of a medical officer (due to vacancy of that post) at the same DMC and DOT centre.

\section{REFERENCES}

[1] Pandit S, Dey A, Chaudhuri AD, et al. Five-years experiences of the revised national tuberculosis control programme in northern part of Kolkata, India. Lung India 2009;26(4):109-13.

[2] Supervision and monitoring strategy in revised national tuberculosis control program 2012.

[3] Technical and operational guidelines for tuberculosis control, central TB division 2005.

[4] Navinchandra MK, Date KP, Thombare VR. Increased sensitivity of sputum microscopy with sodium hypochlorite concentration technique: a practical experience at RNTCP centre. Lung India 2011;28(1):17-20.

[5] Verma A, Mishra M, Singh A, et al. Outcome of cases under revised national tuberculosis control programme at designated microscopy centre of tertiary level hospital and medical college at Kanpur, Uttar Pradesh. J Clin Sci Res 2013;2:126-31.

[6] Bisoi S, Sarkar A, Mallik S, et al. A study on performance, response and outcome of treatment under RNTCP in a tuberculosis unit of Howrah district, West Bengal. Indian Journal of community medicine 2007;32(4):245-8.

[7] Mukherjee A, Saha I, Sarkar A, et al. Gender difference in notification rates, clinical forms and treatment outcome of tuberculosis patients under the RNTCP. Lung India 2012;29(2):120-2.

[8] Mishra A, Mishra S, Chouksey M, et al. A study of effectiveness of DOT'S on tuberculosis patients treated under RNTCP programme. NTI bulletin 2007;43(3-4):47-50.

[9] Chadha SL, Bhagi RP. Treatment outcome in tuberculosis patients placed under directly observed treatment short course (DOTS). Indian Journal of Tuberculosis 2000;47(3):155-8.

[10] DaCosta AL. Treatment outcome of pulmonary and extrapulmonary tuberculosis patients in TB and chest disease hospital DOT centre, Goa, India. Int J Curr Microbiol App Sci 2016;5(4):437-41.

[11] Bawri S, Ali S, Phukan C, et al. A study of sputum conversion in new smear positive pulmonary tuberculosis cases at the monthly intervals of $1^{\text {st }}, 2^{\text {nd }}$ and $3^{\text {rd }}$ month under directly observed treatment, short course (dots) regimen. Lung India 2008;25(3):118-23. 
[12] Kaur G, Goel NK, Kumar D, et al. Treatment outcomes of patients placed on treatment under directly observed therapy short course (DOTS). Lund India 2008;25(2):75-7.

[13] Tiwari S, Kumar A, Kapoor SK. Relationship between sputum smear grading and smear conversion rate and treatment outcome in the patients of pulmonary tuberculosis undergoing dots-a prospective cohort study. Indian Journal of Tuberculosis 2012;59(3):13540 .
[14] Akhtar S, Bhargava R, Ahmad Z, et al. To study the effectiveness of DOTS at J N Medical College Aligarh. Lung India 2007;24(4):128-31.

[15] Mahesh C, Chitra U, Meena BP, et al. Treatment outcome of tuberculosis patients attended at DTC of SMS Medical College, Jaipur (Raj). Indian Journal of Forensic and Community Medicine 2014;1(1):19-22.

[16] Prasad R, Verma SK, Shrivastava P, et al. A followup study on revised national tuberculosis control programme (RNTCP): results from a single centre study. Lung India 2008;25(4):142-4. 